\section{What can we expect from grounded theory? a theoretical critique}

\author{
Mahvash Salsali, ${ }^{1}$ Maryam Esmaeili, ${ }^{2}$ \\ Sina Valiee ${ }^{3}$
}

'School of Nursing and Midwifery, Tehran University of Medical Sciences, Tehran; 2School of Nursing and Midwifery, Nursing and Midwifery Care Research Center, University of Medical Sciences, Tehran; ${ }^{3}$ Social Determinants of Health Research Center, Kurdistan University of Medical Sciences, Sanandaj, Iran

\section{Abstract}

The research approach of grounded theory (henceforth as GT) is one of the common qualitative methodology in social sciences and lately in Nursing which has constantly been confronted with ambiguities regarding its application and particularly its operationalization. It is attempted in this article to offer the true nature, application and measures for a more suitable application of this approach by reviewing its relevant literature in different disciplines. This article is the result of reviewing different databases through 1990 to 2011 and also referring to the main texts in GT research. At the end, it must be mentioned that although the GT research approach is an appealing method, especially in Nursing and enjoys a lot of rigor with regard to dealing with the favorite phenomena of the nurses, the researcher's expectations must be realistic about it. In addition, alongside clarification, which is a social process among a group of individuals, it can be used in presenting model and instrumentation by following the principles and also for providing examination and caring manuals and the required interventions by using the qualitative outcome analysis in order to operationalize it.

\section{Introduction}

The purpose of this discussion paper was reviewing true nature, application, and measures for a more suitable application of grounded theory (GT), as well as the operationalizing the GT in clinical nursing. The GT research is a general research method for generating theories systematically from the acquired information through a rigorous research method. ${ }^{1}$ Glaser and Strauss developed the GT research in 1960 while researching the dying patients at hospitals. ${ }^{1,2}$ Despite having its roots in sociolo- gy, GT emphasizes on the importance of developing an understanding of human behavior through an a process of discovery and induction instead of the quantitative research procedures which go through hypothesis testing and deduction. $^{2}$ The GT approach in nursing offers a valuable means for generating theory about the dominant psychological processes among human interactions and in fact, the theory is grounded in the realities of everyday clinical practice. $^{3}$ In the last 10 years, GT has become the second most popular method of nursing research. ${ }^{4}$ As a research method, GT must follow its own special methodology and for this reason, after reviewing 146 GT-related studies published from 1990 to 1994, Boniniel (1996) found out that 50 percent of the studies that claimed to have been done within a GT framework had not followed the requirements of the GT. Besides, most Nursing researchers had recognized it as equal to all other qualitative research methods and had not perceived in different aspects of the GT from other research approaches. $^{5}$

As it was mentioned, certain problems exist with regard to the perception of GT. So, one of the best ways to answering them is reviewing of the history of the GT. As a matter of fact, Glaser and Strauss (1967) presented this method as a reaction against the permeation of positivism in social researches. They believed that the goal of social researches is to uncover the pre-existing explanations for social behaviors. This issue was the main challenge for Glaser and Strauss and hence they attended to the pragmatism of Charles Pierce (1839-1914), and the early symbolic interactionism of George Herbert (1863-1931) and Charles Coolie (1864-1929), both of whom rejecting this issue that the scientific truth is a reflection of an external independent reality. In their view, scientific truth is the result of both observation and the emerging consensus within a community of observers and their feelings about what they have observed. Thus, in this pragmatic approach to research in social sciences, empirical reality is seen as an ongoing interpretation of the meaning produced by the individuals engaged in a common project. ${ }^{6}$ On this basis, Glaser and Strauss offered the GT as a scientific method for guiding research about the interpretive processes by analyzing the real meaning results and the concepts used by social actors in real settings. They argued that the new theory develops the distinction between daily realities (what is really occurring) and the interpretations of these daily realities of the participating individuals in them. ${ }^{1}$ They also have rejected the conception of hypothesis testing and the falsification made by the positivists. Instead, they have introduced an organic process of theorizing based on how well the data fit the perceived classification by the observer and the
Correspondence: Sina Valiee, School of Nursing and Midwifery, Kurdistan University of Medical Sciences, Pasdaran St., 66177-13446, Sanandaj, Kurdistan, Iran.

Tel.: +98.9188734619 - Fax: +98.8733660092.

E-mail: Valiee@muk.ac.ir

Key words: Grounded theory; nursing; qualitative research; theoretical critique.

Acknowledgments: this study was founded by Kurdistan University of Medical Sciences. The authors appreciate the research committee of Nursing and Midwifery School of Kurdistan University of Medical Sciences for supporting this study.

Contributions: MS, SV, study conception, data collection; MS, SV, ME, drafting of the manuscript; MS, critical revisions for important intellectual content.

Conflict of interest: the authors declare no conflict of interest.

Received for publication: 12 0ctober 2015.

Revision received: 4 January 2016.

Accepted for publication: 4 January 2016 .

This work is licensed under a Creative Commons Attribution NonCommercial 3.0 License (CC BYNC 3.0).

(C) Copyright M. Salsali et al., 2016

Licensee PAGEPress, Italy

Nursing Reports 2016; 6:5583

doi:10.4081/nursrep.2016.5583

way through which the categories aptly explicate or predict the ongoing interpretations and finally how relevant the categories are to the core concept of observation. ${ }^{6}$ There are two fundamental components introduced by them, i.e., constant comparison in which the data are simultaneously gathered and analyzed and theoretical sampling in which a decision is made about what kind of data must be collected on the basis of the emerging theory in future. ${ }^{7}$ Both concepts reject the positivistic assumptions about the manner of carrying out the research processes. Constant comparison contradicts the separation between data collection and analysis and the theoretical sampling rejects the ideal of hypothesis testing, the predefined hypothesis with the ongoing interpretation of data and the emergence of conceptual categories. ${ }^{6}$

Consequently, GT is a method for answering to a special sort of more appropriate questions. GT also must be used in a way that is consistent with key concepts about the world and social realities ${ }^{7}$ and how these realities are known. GT emphasizes on the importance of developing an understanding of human behavior and interactions, and exploration with two 
fundamental components; constant comparison and theoretical sampling.

\section{Should grounded theory lead to generating theory?}

What is GT? As the name shows, the aim of the GT is theory development. Hence, it is logical to assume that if this method does not result in the development of theory, the main requirement of GT is not fulfilled. In Glaser's view (2009), GT is one of the methods for developing the conceptual theory. ${ }^{8}$ However, many researchers do not observe this principle. For instance, Beker (1993) found out that most studies that have used the GT method have been descriptive and merely have addressed the question of what is happening. Nonetheless, GT research has to address not only this question, but also the how question and to conceptualize the relationships between the generated concepts and categories in order to develop a theory. ${ }^{9}$ Wilson and Hutchinson (1996) have also stated that most studies that claim to have been done within a GT framework have in fact used the qualitative analysis method on their data. ${ }^{10}$ Benoliel (1996) also showed that most researchers have generally used the GT for analyzing their data. $^{5}$ Thus, according to these issues, can we imagine that GT can be used for other aims too? Is it possible to have diverse conceptions of the theory? In answering this question, Glaser (1967) cogently mentions some measures for qualitative research in his book, The Discovery of GT, I which he states the aim of GT as theory development. In their book, Glaser and Strauss (1967) mention that there are two kinds of theory: Substantive theory and formal theory. In their view, substantive theory is the one, which explains a reality, for example the empirical areas of sociological inquiry (caring for the patient, racial relations, professional training, etc.) while formal theory explains a formal conceptual area of the sociological inquiry (e.g., Stigma, deviant behavior, authority and power, social mobility, etc.). Therefore, their generalization levels are different; while formal theories are more general, the substantive theories are more limited and hence become limited on the basis of research objective and also with regard to generalizability. ${ }^{1}$ It seems that the current dividing between the formal and substantive theories is incompatible with the idea of GT since the boundary between them, which are more general or more limited, are not clear enough. ${ }^{11}$ The general impression about GT is that it produces the middle-range theories. ${ }^{12}$ In Urguhart's idea, the middle-range theory is a natural consequence of encoding from bottom to top which gives rise to a theory with great proxim- ity to the data. ${ }^{11}$ However, in Glaser and Strauss's viewpoint, GT never results in the generation of micro theory and they also believed that the substantive theory is in fact preliminary and it must then be changed into the formal theory. On this basis, Glaser introduced different methods for the development and measuring the theories, including the examination of similar theories and data in the same substantive areas and also the manner in which the substantive theory is related to the formal theory. ${ }^{13}$ Over time, Glaser held his initial principles, but gradually Strauss changed his approach in 1987 and, alongside Corbin, stated that the development of theory is the only legitimate outcome of GT. They also stated in 1994 that GT is the general methodology for developing theory, but later on in 1990 and 1998, a new thought emerged in Strauss and Corbin's book which stated that GT can be not used for the development of theory too. They held that some of their techniques are used for the generating theory; others are used for useful description or conceptual ordering. ${ }^{14,15}$ Consequently, it can be concluded that they kept their distance from the initial aim of GT, which was the generation of theory. But, this conviction of them must also be precisely interpreted since they point out in their book that theories are not necessarily a set of findings as the results and the theory that is developed on the basis of one existence, which cannot be precisely conceived but can be interpreted. Charmaz (2006) even goes further and states that the difference in the concept of theory is the result of the positivistic and interpretive orientation. In his view, in the positivistic orientation (which, she believes, is what found in Glaser's method), theories are compatible with a combination of interrelated propositions with the aim of interpreting the concept as a variable, the specialized identification of relationships among concepts, explaining and predicting these relationships, systematizing the knowledge, verifying the theoretical relations through testing the hypothesis and generating certain hypotheses for research. In contrast, the interpretive definition emphasizes on theoretical understanding, which considers it as an interpretation and abstraction and does not seek causative relations. The interpretive theory is an imaginative understanding of the researched phenomenon. They assume that realties are diverse and values are interconnected and that realities act as temporary and the social life act as a process. ${ }^{16}$

Thus, by attending to this fact that we confront with different definitions of theory, it can be claimed that Strauss, Corbin and Charmaz have examined GT within the qualitative research framework and so it is quite normal that they stick to the fundamental principles of qualitative research methodology; nonetheless, no consensus is observed about the role of theory in qualitative researches. Hence, it must be mentioned that the existence of different versions of GT and their selection depends on their epistemological situation. Moreover, if the researcher sticks to the initial principles of Glaser in his work, it must lead to the development of theory. Although certain ambiguities exist about Strauss and Corbin's method (1998) in this regard, it is emphasized in the new book by Corbin and Strauss (2008) that in order to deeply describe and develop a unified theory, it is better to pursue the process of analysis without shortcutting and haste. ${ }^{7}$ Also, it is suggested that the researcher not constrain themselves to GT method and instead make use of other methods for theory development in Nursing, especially derivation, synthesis and analysis. ${ }^{17}$ Altogether nurses based on the nature of phenomenon in clinical practice can extract a substantive theory with limited generalization or formal theory that are more general in a GT study, that help better understanding of the phenomenon and its relations.

\section{Operationalizing the grounded theory}

\section{Theory or model?}

One of the challenges of GT is the result of the theory and the likelihood of generalizing it and in order to reach to an answer to this question, we must initially define that what the outcome of the GT is; a theory or model? Since 1960 , certain terms like model, framework and theory are interchangeably used to each other in Nursing. ${ }^{18}$ But, one of the issues that we come across in the final result of a GT-related research is that the diverse titles are common when expressing the final results. Most studies state the result as a theory ${ }^{19}$ and others state it as a model. ${ }^{20}$ Morse and Field (1995) mention the aim of GT as the generation of conceptual models ${ }^{21}$ and in most texts, especially the main GT texts, theory has been pointed out. ${ }^{15}$

The generally accepted definition of the theory is as the internal compatible group regarding the relevant statements which have presented a systematic view about the phenomenon and are useful for the description, explanation, prediction and prescription or control. ${ }^{17}$ Different classifications exist in Nursing about theory. For instance, Johnson and Weber (2010) divide theories into established and speculative theories. $^{22}$ Also, Meleis (2005) divides theories on the basis of abstraction level into grand, middle-range and situation specific theories and on the basis of willingness toward descriptive and prescriptive theories. ${ }^{18}$ In addition, Mc Evan and Wills (2007) categorize models into theoretical and practical models..$^{23}$ But, what is the relation- 
ship between model and theory? The term theo$r y$ is a very good example about the meaning expansion of the word with the passage of time, which has been derived from the Greek word theoria meaning to speculate and later developed into a means for organizing the data for explaining the phenomena. By combining these two definitions, we can say that theory involves a series of explanation on the basis of speculation and thought. ${ }^{22}$ While quoting Mc Farrel, Mc Kenna (1997) defines model as a representation of reality, or while quoting Stockwell, as $a$ simple way of organizing a complex phenomenon. Faust (1992) considers model as a set of concepts and pre-assumptions that turns them into a unified form. Rambo (1984) believes that the model is one of the ways of presenting a situation in logical conditions for showing the structure of an idea or the main objective. Thus, for instance, a psychiatric mental health-nursing model must present one of the ways within psychiatric mental health nursing viewpoint. Chapman (1985) presents three dimensions for describing models: the mono-dimensional models which are the verbal expressions or philosophical beliefs about a phenomenon and enjoy the highest level of abstraction and cannot be separated or be simply observed, but they can come to sight and also be envisaged in the mind; the two-dimensional models that consist of diagrams, plans, graphs or pictures. An instance for these models consists of the clothes pattern, amino acid chains, etc. Most Nursing models, with which we are familiar, had been initially as a mono-dimensional conceptualization in the mind of the researcher and then were developed into two-dimensional formats. The three-dimensional models or the physical models consist of the objective version of material structures. So, they can be easily manipulated. An example of these models consists of toy models and anatomical ones. Models are used in all scientific areas and their application is similar irrespective of discipline. They seek for elucidation and clarification. ${ }^{24}$ In Nursing, the boundary between theory and model is not so much clear and everyone names his/her model work as a model or a theory. For example, Peplao does not recognize her work as theory; however, his work has been named as theory, model and even ideology. With regard to this point that nursing deals with humans and their complex realities, formulating a law is not possible. Thus, the best thing to do is generate theories for aiding the description, explanation, prediction or controlling of human behavior. ${ }^{23-25}$ Another relation between model and theory, which has added to its ambiguity, is that models can be developed either pre-theoretically or post-theoretically. The pre-theoretical models act as an innovative means or an attempt by the researcher for discovering the missing link in initial theorizing and the post-theoretical models are developed for clarifying the internal and the formal structure of the theory, the reciprocal relations system among concepts after the development of theory. ${ }^{17}$ On this basis, they propose that the term, model, be used in its mathematical or schematic sense.

All in all, it must be mentioned that a lot of scientists, including Meleis, have devoted decades of debating the issue of compatibility between philosophy, theory, and models and accordingly have introduced different kinds of models, including physical and semantic models. ${ }^{18}$ However, it seems that the more this issue is dealt with, the more ambiguity emerges about these terms for the novices or even the experienced individuals ${ }^{22}$ which has been even pointed out by Meleis in 2007 This confusion may have contributed to the slow progress, and, at times, stilted theory development in nursing and has led to... a preoccupation with method and process rather than content and consequences. ${ }^{25}$ To put it in simple terms, it can be stated that models are visual representations or diagrams, which demonstrate the theoretical relations and are used for guiding thought and behavior. An appropriate example about using models for a visual demonstration of the components of the theory and thoughts is the Basic Human Need Pyramid by Maslow (1954) which is used for demonstrating the basic human needs and the relation between the key concepts of motivation theory and its hierarchy in the form of a pyramid-like model. Leninger (1985) also used the Sunrise Model for describing the Cultural Diversity Theory about caretaking in Nursing. ${ }^{22}$ On this basis, we can conclude that if the outcome of the GT research is expressed as a sentence, e.g., The theory of becoming $a$ registered nurse, it is better to name it as a theory in the final report and if this sentence is presented in two-dimensional or schematic mode, we can name it a model of the twodimensional kind. ${ }^{20}$ According to the viewpoint of Walker and Avant (2011), the graphic presentation of a theory is called model. Thus, by attending to this fact that the aim of theory is explaining and the aim of the model is demonstrating the relations, model is depicting the simple theories and using them can finally promote theories. ${ }^{22}$ There are different definitions and views about the theory and model, at the end, it must be stated that the outcome of the GT research based on the phenomenon of research is better to be presented in the form of a sentence as a theory and an effort to better understand the relations among the concepts as in schematic form as a model.

\section{How to operationalize the grounded theory}

One of the other important points about the outcome of GT is its likelihood of generalizability, which has been always been under question. For this purpose, the GT method is initially compared to all other methods of model or theory development. The general methods for theory building consist of 5 phases which include the conceptual development, operationalization, confirmation or disconfirmation, application and continuous development and refinement. ${ }^{26}$ Clearly, the application stage is the central stage in the GT research process and the outcome of this stage directly affects the stages of operationalization and conceptual development of the general model. But due to its features, the GT research has certain limits in the stages of confirming or disconfirming and continues developing and refining and this limitation of GT particularly refers to its dependence on the data saturation of the participating groups in research. Hence, the generalizable theory development on the basis of the researched phenomenon is under criticism. ${ }^{26}$ In Lynham's view, the theories that are created via GT research require other research approaches at the last two final stages of model presentation. ${ }^{27}$ Therefore, on this basis, it is suggested that after completing the GT, efforts be taken in order to operationalize. The application of GT in clinical nursing is not exempted from this fact either and different beliefs exist about the need to operationalize trial and test it. Some believe that the resulting theory must be tested after developing the means for measuring the theoretical concepts and some other believe that by virtue of the fact that these theories are context specific, we can confirm or approve them only through the continuous comparison with new data. ${ }^{28}$ In Polit and Beck's (2008) view, there are certain quantitative standards for GT $^{29}$ and Burns and Groves (2007) believe that the quality of the created theory through GT is appropriate and the post-theoretical test is quite useless for its development. ${ }^{30}$ By having different beliefs in this regard, it must be admitted that although qualitative research has developed our understanding of nursing, the application of qualitative findings is too limited in practice and this application limitation alongside with its lack of efficacy have prevented the development of nursing as a clinical discipline. Thus, a gap has been formed between theory and practice in qualitative research. ${ }^{31}$

There are a lot of reasons for the emergence of this gap, especially in GT since most nursing researchers have this misconception that prior to applying GT in clinical settings, it must be tested by developing the instrument or by deductive-hypothetical research. Moreover, despite the case-based usage of GT by nursing researchers for developing and using creative clinical functions, their results have not been documented or released and finally, one of the reasons could be the lack of procedural direc- 
tion for administering and evaluating the qualitative findings. ${ }^{4,28}$ Morse, Penrod and Hupcey (2000) have introduced the process of qualitative outcome analysis (QOA) which is a set of procedures for direct translation of qualitative research, especially GT, into clinical settings through developing and evaluating the interventions. ${ }^{4}$ Qualitative outcomes analysis is a method for the qualitative identification of interventionist strategies and evaluating the outcomes. In this method, a qualitative study is extended into the clinical application phase since the initial results are being implemented. Thus, QOA is a significant pragmatist attempt for connecting practice and research and consists of two main steps of assessing the clinical setting and forming a research team. ${ }^{31}$

On the other hand, while due to various reasons, most of the GT-driven studies have not been turned into interventionist studies, they can be used for developing useful clinical instruments. ${ }^{4}$ For instance, Melrose (2002) used this method for developing the instructional manual for psychiatric mental health nurses. ${ }^{32}$ Also, through a GT-driven study about treating the high-risk pregnant women, the research colleagues prepared a scale for measuring the distress and family disruption and applied it as a part of evaluating the antepartum nursing care program and could be useful in selecting the women who were at high risk due to emotional factors. This example is one of the instances of applying the GT, which directly approves of preparing the instrument through GT and has brought about the cooperation among the clinical members with the researchers. ${ }^{4}$

The use of GT in developing clinical instrument and guide has advantages too, because following the focus on the participants' phenomenon and its related process, the acquired items are based on their daily experience and life. Since GT both describes the phenomenon and helps to predict and explain the better conditions, it can process the intended concept in an abstract manner. Also, due to containing the quotations of the participants and being rooted in their statements, GT is a very good instance for creating the items in instrumentation since it is prepared according to the daily words and language of the participants. So, it must be mentioned that the advantage of using GT in developing the instrument can be its high content validity. Besides, the literature review stage of GT, which is conducted usually in the final stages, places the intended phenomenon in relation to all theoretical and empirical research. ${ }^{4,28}$

Theory, research and practice together compose a cycle that enhances a theory and application stage is an intermediate ring of this cycle. So this stage should run based on phenomenon old study by appropriate method.

\section{Conclusions}

GT as a popular method of nursing research, can link theory, research and practice. Theory application in nursing practice can promote nursing clinical care as well as enhanced basics of the theory presented. Therefore, by using different methods, especially the QOA and according to the results, the researcher can opt for planning the interventions in clinical settings and devising the scale and instrument for the acquired concepts in an effort to enact his own theory in practice.

\section{References}

1. Glaser BG, Strauss AL. The discovery of grounded theory: strategies for qualitative research. New York: Aldine de Gruyter; 1967.

2. Elliott N, Lazenbatt A. How to recognise a 'quality' grounded theory research study. Austr J Adv Nurs 2005;22:48-52.

3. Streubert-Speziale HJ, Carpenter DR. Qualitative research in nursing: advancing the humanistic imperative. 3 ed. Philadelphia, PA: Lippincott Williams and Wilkins; 2003.

4. Schreiber RS, Stern PN. Using grounded theory in nursing. New York: Springer Publishing; 2001.

5. Benoliel JQ. Grounded theory and nursing knowledge. Qual Health Res 1996;6:406-28.

6. Suddaby R. From the editors:what grounded theory is not. Acad Manage $\mathrm{J} 2006 ; 49: 633-42$.

7. Corbin J, Strauss A. Basics of qualitative research: thechniques and procedures for developing grounded theory. 3 ed. Thousand Okas, CA: Sage; 2008.

8. Glaser B. Jargonizing: the use of the grounded theory vocabulary. Mill Valley, CA: The Sociology Press; 2009.

9. Becker PH. Common pitfalls in published grounded theory research. Qual Health Res 1993;3:254-60.

10. Wilson HS, Hutchinson SA. Methodologic mistakes in grounded theory. Research 1996;45:122-4.

11. Urquhart C. An encounter with grounded theory: tackling the practical and philosophical issues. In: Eileen MT, ed. Qualitative research in IS. Hershey, PA: IGI Global; 2001 pp. 104-140.

12. Peterson SJ, Bredow TS. Middle range theories: application to nursing research. 2 ed. Philadelphia, PA: Wolters Kluwer - Lippincott Williams \& Wilkins; 2009.

13. Glaser BG. Theoretical sensitivity: advances in the methodology of grounded theory. Mill Valley, CA: The Sociology Press; 1978.

14. Strauss A, Corbin J. Basics of qualitative
research:Grounded theory procedures and techniques. Newbury Park, CA: Sage; 1998.

15. Strauss A, Corbin J. Basics of qualitative research: grounded theory procedures and techniques. Newbury Park, CA: Sage; 1990.

16. Charmaz K. Constructing grounded theory. A practical quide through qualitative analysis. London: Sage; 2006.

17. Walker LO, Avant KC. Strategies for theory construction in nursing, $5^{\text {th }}$ ed. New Jersey: Prentice Hall, Pearson; 2011.

18. Meleis AI. Theoretical nursing: development and progress. 3 ed. Philadelphia, PA: Lippincott Williams \& Wilkins; 2005.

19. Lundh U, Sandberg J, Nolan M. 'I don't have any other choice': spouses' experiences of placing a partner in a care home for older people in Sweden. J Adv Nurs 2000;32:1178-86.

20. Drury V, Francis K, Chapman Y. Mature learners becoming registered nurses: a grounded theory model. Austr J Adv Nurs 2008;26:39-45.

21. Morse JM, Field PA. Qualitative research methods for health professionals. 2 ed. Thousand Okas, CA: Sage; 1995.

22. Johnson BM, Webber PB. An introducation to theory and reasoning in nursing. 3ed. Philadelphia, PA: Lippincott Williams \& Wilkins 2010.

23. McEwen M, Wills EM. Theoretical basis for nursing. 2 ed. Philadelphia, PA: Lippincott Williams \& Wilkins; 2007.

24. McKenna H. Nursing theories and models. London: Routledge; 1997.

25. Meleis AI. Theoretical nursing: development and progress. 4 ed. Philadelphia, PA: Lippincott Williams \& Wilkins; 2007.

26. Egan TM. Grounded theory research. Adv Dev Human Resour 2002;4:277-95.

27. Lynham SA. The general method of theorybuilding research in applied disciplines. Adv Dev Human Resour 2002;4:221-41.

28. Wuest J, Hodgins MJ, Merritt-Gray M, et al. Queries and quandaries in developing and testing an instrument derived from a grounded theory. J Theory Constr Test 2006;10:26-33.

29. Polit DF, Beck C. Nursing research:generating and assessing evidence for nursing practice. Philadelphia, PA: Wolters Kluwer/Lippincott Williams \& Williams; 2008.

30. Burns N, Grove SK. Understanding nursing research: building an evidence-based practice. St. Louis, MO: Saunders; 2007.

31. Morse JM, Penrod J, Hupcey JE. Qualitative outcome analysis: evaluating nursing intervention for complex clinical phenomena. $\mathrm{J}$ Nurs Scholar 2000;32:125-30.

32. Melrose S. A clinical teaching guide for psychiatric mental health nursing: a qualitative outcome analysis project. J Psychiatr Mental Health Nurs 2002;9:381-9. 